\title{
Effects of dietary cold-pressed turnip rapeseed oil and butter on serum lipids, oxidized LDL and arterial elasticity in men with metabolic syndrome
}

\author{
Ari Palomäki ${ }^{1,2}$, Hanna Pohjantähti-Maaroos ${ }^{1,2,3^{*}}$, Marja Wallenius ${ }^{1,2,4}$, Päivi Kankkunen ${ }^{1,5}$, Heikki Aro ${ }^{6,7}$, \\ Sari Husgafvel ${ }^{1}$, Juha-Matti Pihlava ${ }^{6}$, Kalevi Oksanen ${ }^{1}$
}

\begin{abstract}
Background: Rapeseed oil is the principal dietary source of monounsaturated and n-3 polyunsaturated fatty acids in the Northern Europe. However, the effect of rapeseed oil on the markers of subclinical atherosclerosis is not known. The purpose of this study was to compare the effects of dietary intake of cold-pressed turnip rapeseed oil (CPTRO) and butter on serum lipids, oxidized LDL and arterial elasticity in men with metabolic syndrome.

Methods: Thirty-seven men with metabolic syndrome completed an open and balanced crossover study. Treatment periods lasted for 6 to 8 weeks and they were separated from each other with an eight-week washout period. Subjects maintained their normal dietary habits and physical activity without major variations. The daily fat adjunct consisted either of 37.5 grams of butter or $35 \mathrm{~mL}$ of Virgino ${ }^{R}$ CPTRO. Participants were asked to spread butter on bread on the butter period and to drink CPTRO on the oil period. The fat adjunct was used as such without heating or frying.
\end{abstract}

Results: Compared to butter, administration of CPTRO was followed by a reduction of total cholesterol by $8 \%$ ( $p<$ $0.001)$ and $L D L$ cholesterol by $11 \%(p<0.001)$. The level of oxidized LDL was $16 \%$ lower after oil period $(p=$ 0.024). Minimal differences in arterial elasticity were not statistically significant.

Conclusion: Cold-pressed turnip rapeseed oil had favourable effects on circulating LDL cholesterol and oxidized $L D L$, which may be important in the management of patients at high cardiovascular risk.

Trial registration: ClinicalTrial.gov NCT01119690.

\section{Background}

Metabolic syndrome (MetS) is an international health problem. Risk factors included in the MetS are impaired glucose tolerance, elevated triglyceride levels, decreased HDL cholesterol concentration, elevated blood pressure and central obesity [1]. The risk of developing coronary heart disease is six to eight times greater and mortality in coronary heart disease two to three times greater among patients with MetS than among their healthy controls [2-5]. Furthermore, patients with MetS are at

\footnotetext{
* Correspondence: hanna.pohjantahti-maaroos@kuh.fi

'Kanta-Häme Central Hospital, Ahvenistontie 20, Fl-13530, Hämeenlinna, Finland

Full list of author information is available at the end of the article
}

high risk to develop type 2 diabetes and myocardial infarction $[4,5]$.

Atherosclerosis begins with an accumulation of lipoproteins, particularly low-density lipoprotein (LDL) into the intimae of arteries. In the arterial wall, LDL particles undergo oxidative modification which is suggested to play an important role in the atherosclerotic process [6]. Circulating oxidized LDL (oxLDL) seems to express the level of oxidative stress and associate with the risk factors of MetS [7]. Oxidized LDL has also been found to correlate with the extent of coronary heart disease and to be an independent predictor of an atherosclerotic plaque occurrence [8-10].

\section{() Biomed Central}


Oxidative modification of LDL damages the endothelium of the arterial wall [6]. Altered endothelial structure impairs the elasticity of the arteries already at an early stage of atherosclerosis [11]. Impaired elasticity of arteries may also result from factors affecting the elastic properties of the arterial wall, not only the endothelium. For example aging and hypertension may contribute to an overproduction of collagen and breaks in elastin fibers. Aortic stiffness has been reported to predict future coronary events and cardiovascular death in previous studies [12]. Thus, increased level of oxLDL and arterial stiffness might be used as early indicators of cardiovascular disease.

Despite of its' high total fat content, Mediterranean type diet rich in monounsaturated fatty acids (MUFA), decreases cardiovascular morbidity and mortality $[13,14]$. MUFA diminishes susceptibility of LDL to oxidation, which may contribute to this benefit [15-17]. The protective effect of $n-3$ polyunsaturated fatty acids (PUFA) from marine sources has been studied widely. However, the role of the plant derived n-3 PUFA, a principal dietary n-3 PUFA in the western diet, is less clear [18]. Rapeseed oil consists of high amounts of MUFA, a composition similar to that of olive oil. Rapeseed oil is also the main dietary source of plant-derived n-3 PUFA in the Northern Europe. However, the effect of rapeseed oil on the markers of subclinical atherosclerosis is not known.

Subjects with metabolic syndrome seem to have increased oxLDL levels and impaired arterial elasticity [19]. Manipulation of the fat quality in diet, to achieve alterations in plasma lipoproteins and arterial function, is an intriguing strategy in the prevention of atherosclerotic cardiovascular diseases. The aim of our study was to assess whether a dietary intake of cold-pressed turnip rapeseed oil (CPTRO) has beneficial effects on serum lipids, oxidized LDL and arterial elasticity compared to an intake of butter among men with metabolic syndrome.

\section{Methods}

\section{Subjects}

The present study is a part of Hämeenlinna Metabolic Syndrome research program HMS. It is a regional entity investigating atherosclerotic risk factors in men with MetS, who were referred from private and public consultations in primary and secondary health care. The inclusion criteria were male sex, age 30 to 65 years and a fulfilment of the criteria of MetS according to the National Cholesterol Education Program (NCEP) Adult Treatment Panel [1]. NCEP defines MetS as the presence of at least three of the following five criteria: 1) waist circumference $>102 \mathrm{~cm}, 2$ ) serum triglycerides $\geq 1.7 \mathrm{mmol} / \mathrm{L}, 3) \mathrm{HDL}$ cholesterol $<1.03 \mathrm{mmol} / \mathrm{L}$,
4) blood pressure $\geq 130 / 85 \mathrm{mmHg}$ and 5) fasting plasma glucose $\geq 6.1 \mathrm{mmol} / \mathrm{L}$ or diabetes.

43 study subjects, already recruited into HMS, participated in this dietary intervention study. Subjects were individually interviewed on their medical history, dietary habits, smoking and alcohol consumption. Physical examination consisted of height, weight, waist circumference and blood pressure measurements. Body mass index (BMI) was calculated as weight $(\mathrm{kg}) /$ height $^{2}\left(\mathrm{~m}^{2}\right)$. Blood pressure was measured four times after at least ten minutes of rest in a semi-sitting position. The individual blood pressure was taken as a mean of these values. The weight and blood pressure measurements were repeated at the end of both study periods. Research personnel performing the laboratory and arterial elasticity measurements were blinded about the diet periods.

The Ethics Committee of the Kanta-Häme Hospital District approved the study protocol and the study followed the ethical principles outlined in the Declaration of Helsinki. Each study subject gave a written informed consent.

\section{Design and Diets}

Subjects' usual diet was supplemented with CPTRO and butter in an open, balanced and randomized crossover design. The study consisted of two study periods (oil and butter) lasting from 6 to 8 weeks, and they were separated from each other by an 8-week washout period (Figure 1). To avoid the effect of seasonal variation on the results, the first study period occurred from October to December and the second period from January to March.

At the beginning of each fat supplementation period the participants were given both verbal and written detailed instructions to be followed. Butter with a maximal water content of $16 \%$ and cold-pressed turnip rapeseed oil $(0.92 \mathrm{~g} / \mathrm{ml})$ were provided free of charge. The daily fat adjunct consisted either of 37.5 grams of butter

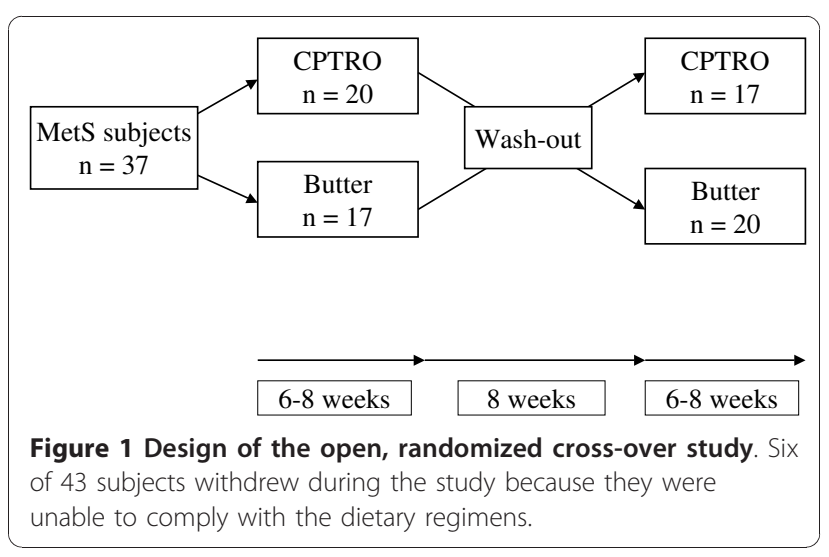


(Valio Ltd, Finland) on the saturated fatty acid (SFA) period and $35 \mathrm{~mL}$ of Virgino ${ }^{\mathrm{R}}$ CPTRO (Kankaisten Öljykasvit Ltd) on the oil period, which comprised approximately $11-12 \%$ of daily energy intake. We recommended participants to use the fat adjunct as such, without heating or frying. To keep the diets as stable as possible, participants were asked to spread the butter supplement on bread during the butter period and to drink the oil supplement as well as to eat their bread without spread during the oil period. Besides these instructions subjects were asked to maintain their normal dietary habits and physical activity without major variations. Heating or frying of other fat included in the subjects' every-day diet was not forbidden. To ensure that subjects' everyday diet and physical activity remained similar during both periods, they were asked to fill in a structured questionnaire on their diet as well as on the amount, intensity and type of physical exercise during the study.

\section{Analysis of Fatty Acids and Phenolic Compounds}

The fatty acid compositions of cold-pressed turnip rapeseed oil and butter were analysed at MTT Agrifood Research Finland (Jokioinen, Finland). Fatty acids were analysed as their methyl esters. The analysis was carried out using a Hewlett Packard 5890 capillary gas chromatograph equipped with a DB-23 column coated with a cyanopropyl-stationary phase $(60 \mathrm{~m} * 0.25 \mathrm{~mm}$ id, film thickness $0.25 \mu \mathrm{m}$ ) and a mass selective detector. A mixture of standard fatty acids (C4:0 - C24:1) purchased from $\mathrm{Nu}$-Check-Prep Inc. (Minnesota, USA) was used as the standard to identify the peaks.

To analyze the amount of phenolic compounds, sample of CPTRO was dissolved into hexane and extracted with $80 \%$ methanol according to a modified method of Vuorela et al [20]. Phenolic compounds were identified and quantified by high performance liquid chromatography with diode array detection using analytical conditions similar to those used for the determination of alkylresorcinols [21]. Vinylsyringol (2,6-dimethoxy-4vinylpheol) was quantified as syringic acid.

The fatty acid compositions of the dietary fat supplements i.e. Virgino ${ }^{R}$ cold-pressed turnip rapeseed oil and butter are shown in Table 1. Butter consisted mainly of saturated fatty acids (61.7\%). Oleic acid was the main unsaturated fatty acid found in butter. CPTRO consisted mainly of unsaturated fatty acids (95.6\%), over half of which were monounsaturated ones. The major fatty acids in oil were oleic acid, linoleic acid and alfalinolenic acid. CPTRO contained also a small amount of phenolic compounds. Total amount of sinapine and sinapic acid was $0.94 \mu \mathrm{mol} / 100 \mathrm{~g}$ and of vinylsyringol $0.89 \mu \mathrm{mol} / 100 \mathrm{~g}$. Also some smaller peaks of unknown phenolic compounds were seen in the high performance liquid chromatograms.
Table 1 Distribution of fatty acids in cold-pressed Virgino $^{R}$ turnip rapeseed oil (CPTRO) and butter used in the study

\begin{tabular}{|c|c|c|}
\hline \multirow[t]{2}{*}{ Fatty acids } & \multicolumn{2}{|c|}{ Distribution \% } \\
\hline & CPTRO & Butter \\
\hline 10:0 capric acid & 0 & 1.6 \\
\hline 12:0 lauric acid & 0 & 2.7 \\
\hline 14:0 myristic acid & 0 & 11.0 \\
\hline 14:1 ( $\omega-5)$ myristoleic acid & 0 & 0.9 \\
\hline 15:0 pentadecanoic acid & 0 & 0.9 \\
\hline 16:0 palmitic acid & 2.9 & 30.0 \\
\hline 16:1 ( $\omega-7)$ palmitoleicacid & 0.1 & 1.5 \\
\hline 18:0 stearic acid & 1.3 & 14.6 \\
\hline 18:1 ( $\omega-7)$ vaccenic acid & 2.9 & 0.9 \\
\hline 18:1 $(\omega-9)$ oleic acid & 56.7 & 30.4 \\
\hline $18: 2(\omega-6)$ linoleic acid & 21.9 & 2.0 \\
\hline 18:3 ( $\omega-3)$ alpha-linolenic acid & 13.1 & 0.4 \\
\hline 20:1 ( $\omega-9)$ eicosenoic acid & 0.9 & 0 \\
\hline Others $(8: 0,17: 0,18: 2,20: 0)$ & 0.3 & 1.4 \\
\hline Unidentified fatty acids & 0 & 1.8 \\
\hline Saturated fatty acids & 4.5 & 61.7 \\
\hline Monounsaturated fatty acids & 60.6 & 33.7 \\
\hline Polyunsaturated fatty acids & 35.0 & 2.9 \\
\hline
\end{tabular}

The following fatty acids analyzed did not exist in CPTRO nor in butter: 16:0(i), $16: 1,17: 1,18: 3(\omega-6), 18: 4(\omega-3), 18: 4(\omega-3), 19: 1,20: 2(\omega-6), 20: 3,20: 3(\omega-3)$, $20: 4(\omega-6), 20: 5(\omega-3), 22: 0,22: 1(\omega-9), 22: 2,22: 3,22: 4(\omega-6), 22: 5(\omega-3), 22: 6(\omega-$ $3), 24: 0$, and $24: 1(\omega-9)$.

\section{Blood Sampling and Biochemical Analysis}

At the end of both dietary periods, blood samples were collected into $10 \mathrm{~mL}$ EDTA tubes, $5 \mathrm{~mL}$ lithium-heparin gel tubes and $2 \mathrm{~mL}$ natrium-fluoride tubes after a 12-hour overnight fast and at least ten minutes of rest. Levels of HDL, LDL and total cholesterol and triglycerides as well as glucose and $\mathrm{HbA1C}$ were analyzed by Cobas Integra procedure (Roche). HbA1C was assessed in $\%$ and conversed to $\mathrm{mmol} / \mathrm{mol}$ [22]. The laboratory practices strict internal quality control with daily and monthly control samples performed by a national external quality assurance program (Labquality $\mathrm{Oy}$ ).

\section{Determination of Oxidized LDL}

Plasma levels of oxidized LDL were determined as duplicates after both diet intervention periods. Determinations were made according to a validated monoclonal antibody 4E6-based capture ELISA (Mercodia AB, Uppsala, Sweden) $[7,9]$. The monoclonal antibody mAb4E6 is the same as in the assays previously described by Holvoet et al $[8,10]$. Samples were diluted with sample buffer in two steps to gain a final dilution 1/6561. $25 \mu \mathrm{l}$ of each calibrator, control and diluted sample were pipetted into wells containing mouse monoclonal antioxidized LDL. $100 \mu \mathrm{l}$ assay buffer was added into each well. Samples were washed 6 times with automatic 
washer before $100 \mu \mathrm{l}$ peroxidase conjugated mouse monoclonal anti-apoB was added. After a 60-minute incubation at room temperature, samples were washed again and the bound conjugate was detected by reaction with $200 \mu \mathrm{l}$ 3,3', 5,5'-tetramethylbenzidine. Reaction was stopped by $50 \mu \mathrm{l} 0.5 \mathrm{M} \mathrm{H}_{2} \mathrm{SO}_{4}$ and the colorimetric endpoint was read spectrophotometrically at $450 \mathrm{~nm}$. Same experienced researcher at Kanta-Häme Central Hospital performed all determinations of oxidized LDL.

\section{Determination of Arterial Elasticity}

An experienced nurse measured the elasticity of large and small arteries after at least 10 minutes of rest in a semi-sitting position. The recording was carried out in a temperature-controlled room after an overnight fast. Subjects were asked to refrain from eating, smoking, drinking caffeinated drinks and taking medication for 12 hours and drinking alcohol for two days prior to measurement. Radial artery pulse wave was recorded non-invasively with an arterial tonometry (HDI/PulseWave $\left.{ }^{\mathrm{m}} \mathrm{CR}-2000\right)$ that uses a modified Windkessel pulse-contour method [11]. The capacitive elasticity of large arteries $(\mathrm{C} 1)$ and the reflective elasticity of small arteries (C2) were automatically assessed as a mean of five most similar pulse waves appearing during thirty seconds of measurement. Four measurements were performed to gain mean large and small arterial elasticity for every subject. Studies were performed at the end of both diet periods.

\section{Statistical Analysis}

Statistical analysis was carried out with the SPSS software (version 17.0, SPSS 2009). Basic results are reported as mean \pm SD. Paired samples' T-test was used to compare the outcome measurements after diets in case of normality. Wilcoxon's test was used in case of non-normality. These results are reported as mean \pm SEM. Statistical significance was accepted at $\mathrm{p}$ value $<0.05$.

\section{Results}

Six men withdrew because they were unable to comply with the dietary regimens. Results include thirty-seven subjects who completed both study periods. Baseline characteristics of these 37 men are shown in Table 2.

There were six current smokers, twenty-one ex-smokers and nine non-smokers. Twenty-one men had earlier been diagnosed with hypertension, nineteen with type 2 diabetes and six with coronary heart disease. Pharmacological therapy consisted of aspirin or other antiplatelet agent in fourteen, beta-blockers in sixteen, and ACE inhibitors or angiotensin ${ }_{1}$ receptor inhibitors in fourteen subjects, but only four were on glucoselowering drugs. Fifteen men were on statin medication, two of these on combination therapy of statin and fibrate.
Table 2 Basic clinical and laboratory characteristics of 37 men with metabolic syndrome accomplishing all clinical phases of the study

\begin{tabular}{lll}
\hline & Mean (SD) & Range \\
\hline Height, cm & $177.1(5.7)$ & $163.0-191.0$ \\
Weight, kg & $97.4(16.3)$ & $68.0-142.0$ \\
Waist circumference, cm & $111.1(13.1)$ & $92.0-150.0$ \\
BMl, kg/m & $31.0(5.0)$ & $23.9-46.4$ \\
SBP, mmHg & $145.5(12.3)$ & $122.0-172.0$ \\
DBP, mmHg & $90.8(5.6)$ & $80.0-105.0$ \\
Fasting glucose, mmol/L & $6.62(1.19)$ & $3.3-9.5$ \\
HbA1C & & \\
$\quad$ (\%) & $6.42(0.66)$ & $5.3-8.7$ \\
$\quad$ (mmol/mol) & $46.7(7.2)$ & $34.4-71.6$ \\
Total cholesterol, mmol/L & $5.15(1.49)$ & $2.6-8.4$ \\
HDL-C, mmol/L & $1.15(0.27)$ & $0.5-1.7$ \\
LDL-C, mmol/L & $3.33(1.25)$ & $1.1-6.0$ \\
Triglycerides, mmol/L & $2.19(1.13)$ & $0.9-6.3$ \\
ALAT, U/L & $53.0(27.4)$ & $25.0-163.0$ \\
GT, U/L & $72.4(62.9)$ & $15.0-275.0$ \\
Afos, U/L & $67.6(19.7)$ & $30.0-115.0$ \\
Fibrinogen, g/L & $3.49(0.96)$ & $2.3-5.5$ \\
\hline & &
\end{tabular}

Physical activity, medication and every-day diet of participants, evaluated by a structured questionnaire, remained stable during the study. As presented in Figure 2, the level of oxidized LDL was significantly lower (16\%) after the cold-pressed turnip rapeseed oil period compared to the butter period $(\mathrm{p}=0.024)$. Total and LDL cholesterol were also significantly lower after the CPTRO period compared to the levels after the butter period, $8 \%(\mathrm{p}<0.001)$ and $11 \%(\mathrm{p}<0.001)$,

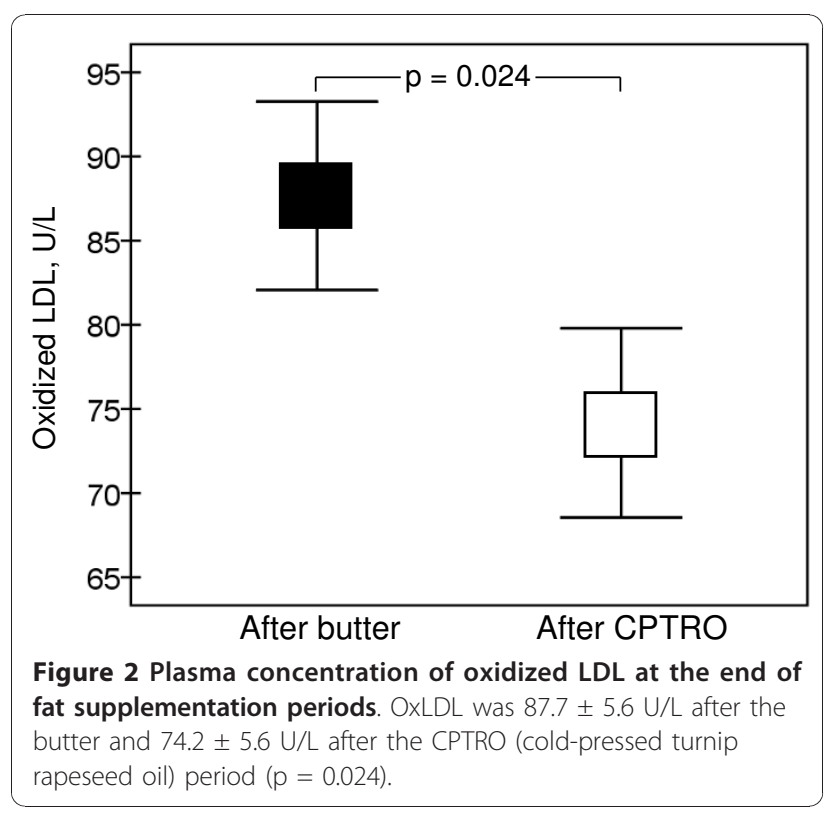


respectively (Figure 3 ). No significant differences in HDL cholesterol, triglycerides, glucose or HbA1C were found between the periods. The concentration of HDL cholesterol was $1.15 \pm 0.04 \mathrm{mmol} / \mathrm{L}$ after both diet periods. Triglycerides were $2.72 \pm 0.30 \mathrm{mmol} / \mathrm{L}$ after the butter and $2.56 \pm 0.38 \mathrm{mmol} / \mathrm{L}$ after the CPTRO periods (NS).

There were no significant differences in the mean large or small arterial elasticity between the diet periods (Table 3). Systolic blood pressure was $138.5 \pm 2.2 \mathrm{mmHg}$ after the butter and $138.5 \pm 2.6 \mathrm{mmHg}$ after the CPTRO period. Diastolic blood pressures were $81.8 \pm 1.4 \mathrm{mmHg}$ and 81.3 $\pm 1.6 \mathrm{mmHg}$, respectively. Weight remained stable through the study, $97.1 \pm 2.8$ after the butter and $97.1 \pm 2.7$ after the oil period. Total blood count showed no significant differences between rapeseed oil and butter consumption except in the mean corpuscular haemoglobin $(31.1 \pm 0.2$ pg vs. $30.8 \pm 0.2 \mathrm{pg}, \mathrm{p}=0.01)$ and in the platelet count $(221.6 \pm 9.0 \mathrm{E} 9 / \mathrm{L}$ vs. $235.4 \pm 9.5 \mathrm{E} 9 / \mathrm{L}, \mathrm{p}=0.003)$.

\section{Discussion}

In this study among men with MetS dietary coldpressed turnip rapeseed oil was associated with favourable changes in lipid parameters compared to the use of butter. The lower level of total cholesterol after CPTRO consumption was due to the lower level of LDL cholesterol. However, the concentration of circulating oxLDL was proportionally even lower than that of LDL cholesterol after the CPTRO period.

To our knowledge, this is the first report on the beneficial effect of rapeseed oil on circulating oxLDL levels.

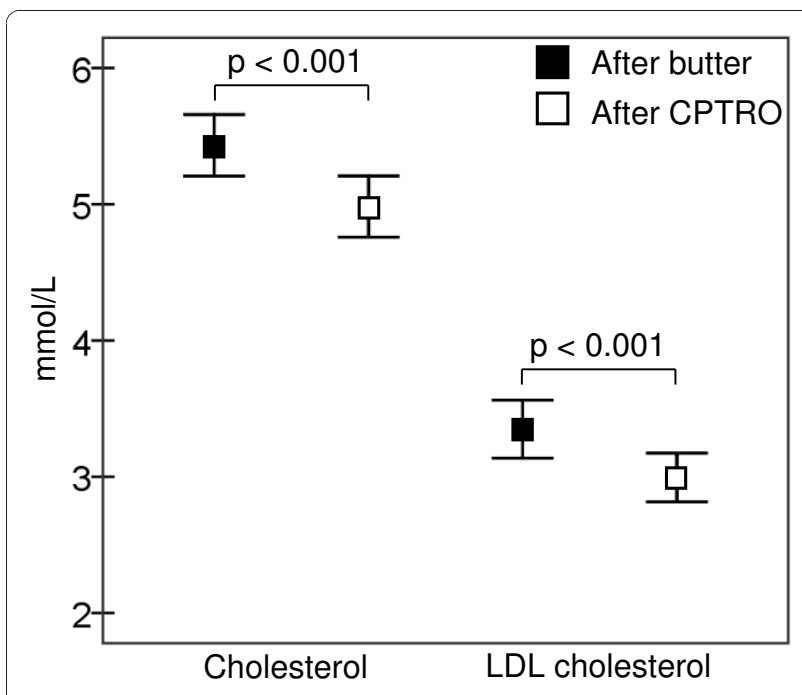

Figure 3 Concentrations of total and LDL cholesterol. Total cholesterol was $5.43 \pm 0.23 \mathrm{mmol} / \mathrm{L}$ at the end of the butter and $4.98 \pm 0.23 \mathrm{mmol} / \mathrm{L}$ at the end of the CPTRO (cold-pressed turnip rapeseed oil) period ( $p<0.001)$. LDL cholesterol was $3.35 \pm 0.21$ $\mathrm{mmol} / \mathrm{L}$ and $3.00 \pm 0.18 \mathrm{mmol} / \mathrm{L}$, respectively $(p<0.001)$.
Table 3 Large (C1) and small (C2) arterial elasticity at the end of butter and oil periods

\begin{tabular}{llll}
\hline & Butter period & Oil period & p value \\
\hline $\mathrm{C} 1, \mathrm{~mL} / \mathrm{mmHg} \times 10$ & $15.5 \pm 0.46$ & $15.9 \pm 0.71$ & $\mathrm{NS}$ \\
$\mathrm{C} 2, \mathrm{~mL} / \mathrm{mmHg} \times 100$ & $6.26 \pm 0.48$ & $6.34 \pm 0.44$ & $\mathrm{NS}$ \\
\hline
\end{tabular}

Data are presented as mean \pm SEM

The significant reductions in total and LDL cholesterol levels are in accordance with earlier rapeseed oil studies $[23,24]$. In agreement with most of the previous studies $[23,25,26]$ the use of rapeseed oil did not have significant effect on HDL cholesterol levels, although a slight increase in HDL cholesterol by rapeseed oil has also been reported [24].

LDL particles enriched with MUFA seem to be resistant against oxidation [15-17]. Since MUFA are the main fatty acids in rapeseed oil, this protective effect may contribute to the decreased level of oxLDL after CPTRO enriched diet in the present study. Previously, a diet with high content of MUFA has been shown to decrease oxLDL levels among healthy non-obese men as well as among subjects at high cardiovascular risk $[27,28]$. Although effects of turnip rapeseed oil among metabolic syndrome patients have not been studied earlier, high MUFA-rich diet has been reported to improve oxidative stress parameters in patients with MetS [29]. Also in a study by Perona et al [30], MUFA-rich virgin olive oil protected LDL against oxidation among type 2 diabetics.

The origin of circulating oxLDL is unknown. Oxidative modification of LDL can generate minimally or fully oxidized LDL [31]. It is generally thought that oxidation of LDL occurs mainly in the arterial wall and only minimally oxidized LDL exists in the circulation $[6,31]$. However, increased circulating oxLDL, determined by a method using the same monoclonal antibody as in the present study, is known to associate both with subclinical and clinical atherosclerosis as well as to predict future cardiovascular events $[8,9,32]$. Thus, dietary manipulations that protect LDL against oxidation may delay development of atherosclerotic lesions in patients with MetS.

Increased glucose levels, often present among subjects with MetS, may enhance the oxidation of lipoprotein(a) [33]. Previously, a low-carbohydrate (LC) diet had more favourable effects on MetS features compared to a lowfat diet [34]. A low-carbohydrate diet has also been reported to prevent the accumulation of oxLDL in the arterial wall [35]. Whether a LC-diet supplemented with CPTRO would cause even greater reductions in oxLDL and prevent future cardiovascular events among MetS subjects would be interesting to study.

Most dietary approaches to prevent hyperlipidaemia and atherosclerosis have focused on the alteration of fat 
composition and quantity in diet. In the present study, CPTRO had a cholesterol-lowering effect as a supplement to the habitual diet. Turnip rapeseed oil is the main Finnish source of unsaturated fatty acids, mainly monounsaturated ones. By improved cultivation, MUFA in rapeseed oil consist of an important amount of oleic acid. Mediterranean type diet, also rich in MUFA, has been shown to decrease total cardiovascular mortality [13]. Compared to olive oil, common in the Mediterranean region, Virgino $^{R}$ rapeseed oil contains less MUFA and SFA but a considerable amount of n-3 PUFA, namely alfa-linolenic acid (see Table 1 ).

Low dose of n-3 PUFA supplement reduced early mortality after myocardial infarction in the GISSIPrevenzione trial [36]. On the other hand LDL susceptibility to oxidation has been assumed to associate with an increased amount of PUFA in the small and dense LDL particles [37]. In addition, PUFA-rich diet increased susceptibility of LDL to oxidation when compared to MUFA-rich diet among subjects with impaired glucose intolerance [38]. However, moderate amounts of highly unsaturated n-3 fatty acids in a diet supplemented with rapeseed oil did not increase LDL oxidizability when provided in the context of a diet rich in MUFA [15].

In addition to MUFA, phenolic compounds of olive oil have been shown to reduce oxidative damage [39]. Rapeseed oil, supplemented in the present study, contained only slight amounts of phenolic compounds. Therefore, the antioxidative effect of rapeseed oil is presumably mediated mainly by the high contents of MUFA and n-3-PUFA.

In our study, arterial elasticity seemed to be minimally better after the CPTRO than after the butter period, but the difference was not statistically significant. One explanation might be that the intervention period was too short to affect the function of the arterial wall. However, McVeigh et al [40] have found improved arterial compliance already after a 6-week fish oil administration in patients with non-insulin-dependent diabetes. Arterial stiffness is not merely affected by endothelial dysfunction. For example, untreated long-lasting hypertension and aging may cause increase in the amount of collagen and decrease in the amount of elastin fibers in the arterial wall [12]. Alterations in the elastic properties of the arterial wall contribute to the impairment of elasticity.

Since endothelial dysfunction is a key mechanism in atherosclerosis, a measurement of mere endothelial function might be more sensitive in a short-term intervention study [11]. Previously, a walnut diet rich in antioxidants and alfa-linolenic acid for four weeks showed an improvement in endothelial function of hypercholesterolaemic subjects [41]. Even one meal supplemented with walnuts rich in $\mathrm{n}-3$-PUFA, has been reported to improve flow-mediated dilation of arteries as a sign of improved endothelial function [42]. The same effect was however not seen after a meal supplemented with MUFA-rich olive oil [42]. Differences in fat type and study groups or methods used to evaluate arterial function might explain the seeming discrepancy of the results between the abovementioned studies and the present one. It would be interesting to study the effects of rapeseed oil among subjects with evidently decreased arterial elasticity.

The platelet count was lower after the CPTRO period in our study. It has been revealed earlier that fish oils decrease fibrinogen level and platelet count [43]. Vegetable n-3 PUFA, like alfa-linolenic acid, is an important constituent of the Virgino ${ }^{\mathrm{R}}$ CPTRO. During fat metabolism it can be converted to longer chain fatty acids found also in fish oils. Hence, the significant decrease in platelet count after CPTRO consumption may be attributed to the n-3 PUFA.

Strength of this study, unlike of many other dietary studies, was the balanced crossover design used to diminish the variability between the subjects. We did not measure the fat and energy intake by dietary records, which was a limitation of the study. However, we ensured the stability of both habitual diet and physical activity during the study periods by analyzing the detailed questionnaire that subjects filled in at the end of the intervention periods. Previously a similar food frequency questionnaire has been reported to be a suitable tool for ranking energy and nutrient intake [44]. In addition, there was no difference in weight between the two dietary periods which is in agreement with previous studies on n-3-PUFA and MUFA rich diets $[45,46]$. Hence, the difference in energy balance did not explain our findings.

A healthy cohort would have been an interesting addition to the study. However, we have previously reported increased oxLDL levels as well as impaired large arterial elasticity among MetS subjects compared to their healthy, age-matched counterparts [19]. Therefore, in the present study we wanted to focus on MetS subjects because of their increased risk for atherosclerotic cardiovascular diseases.

Vegetable oils are often consumed in cooking and frying. However, repeated heating may destroy the beneficial compounds of the oils and generate unhealthy effects instead $[47,48]$. Therefore, study subjects were asked to drink CPTRO as such, without heating or frying. Heating or frying of fat included in the subjects' every-day diet was not forbidden. We cannot determine the optimal daily dose of CPTRO based on the results of this study, in which a constant dose of CPTRO and a comparable amount of butter were used. Previously whipped cream with a similar dose of SFA as used in the present study did not cause a significant increase in postprandial oxidative stress [49]. Thus, at least the dose of CPTRO, used 
in the present study, seems to be beneficial as a supplement to a diet. In practise, it may be used as such for example in salad and dip sauces. It is worth to notice that the study included only men with MetS. Hence, the results cannot necessarily be generalized to the whole population including women and men without MetS.

\section{Conclusion}

A short-time modification of the diet with cold-pressed turnip rapeseed oil compared to butter decreased the concentration of circulating LDL cholesterol and oxidized LDL. In men with metabolic syndrome, modification of the diet with cold-pressed turnip rapeseed oil may be beneficial in treating hyperlipidaemia and diminishing oxidative stress and thereby delaying the progression of atherosclerosis.

\section{List of Abbreviations}

BMl: body mass index; C1: large arterial elasticity; C2: small arterial elasticity; CPTRO: cold-pressed turnip rapeseed oil; HbA1C: glycosylated haemoglobin HDL: high density lipoprotein; HMS: Hämeenlinna Metabolic Syndrome Research Program; LC: low-carbohydrate; LDL: low density lipoprotein; MetS: metabolic syndrome; MUFA: mono-unsaturated fatty acids; NCEP: National Cholesterol Education Program; oxLDL: oxidized low density lipoprotein; PUFA: poly-unsaturated fatty acids; SFA: saturated fatty acids.

\section{Acknowledgements and Funding}

This study was supported by grants from the Ministry of Health and Social Welfare in Finland through the Medical Research Fund of Kanta-Häme Central Hospital, the Häme Regional Fund under the auspices of the Finnish Cultural Foundation, Kankaisten Öljykasvit Ltd, and Hilkka and Väinö Kiltti Foundation. None of them had a role in data collection, analysis of the results, or preparation of the manuscript.

We sincerely acknowledge Mrs Leena Puura for determining the fatty acid profiles, Mrs Tuula Kurtélius for analyzing phenolic compounds of CPTRO, and RN Paula Lahtinen for measuring arterial elasticity. We acknowledge sincerely the professional aid of MD Ruth Laitinen. We appreciate the professional technical aid of Mrs Kirsti Räsänen. The authors gratefully acknowledge the cooperation of the study subjects.

\section{Author details}

'Kanta-Häme Central Hospital, Ahvenistontie 20, Fl-13530, Hämeenlinna, Finland. 'Linnan Klinikka, Raatihuoneenkatu 10, Fl-13100, Hämeenlinna, Finland. ${ }^{3}$ Heart Center, Kuopio University Hospital, P.O. Box 1777, Fl-70211, Kuopio, Finland. ${ }^{4}$ Mehiläinen, Sibeliuksenkatu 3, Fl-13100, Hämeenlinna, Finland. ${ }^{5}$ Finnish Institute of Occupational Health, Topeliuksenkatu 41 aA, FI00250 Helsinki, Finland. ${ }^{6}$ MTT Agrifood Research Finland, Fl-31600, Jokioinen, Finland. ${ }^{7}$ Finnish Funding Agency for Technology and Innovation, P.O. Box 69, FI-00101, Helsinki, Finland.

\section{Authors' contributions}

AP designed the study with the help of KO. AP, HPM and MW participated in the acquisition of data, analysis and drafting of the manuscript. PK, HA, $\mathrm{SH}$, and JMP made a substantial contribution in the acquisition of data and helped in drafting the manuscript, $\mathrm{KO}$ participated in the acquisition of data and gave the final approval of the version to be published. All authors read and approved the final manuscript.

\section{Competing interests}

The authors declare that they have no competing interests.

Received: 6 November 2010 Accepted: 1 December 2010 Published: 1 December 2010
References

1. Third report of the National Cholesterol Education Program (NCEP) expert panel on detection, evaluation and treatment of high blood cholesterol in adults (Adult Treatment Panel III) Final report. Circulation 2002, 106:3143-3421

2. Vanhala MJ, Kumpusalo EA, Pitkajarvi TK, Takala JK: Metabolic syndrome in a middle-aged Finnish population. J Cardiovasc Risk 1997, 4:291-295.

3. Lakka HM, Laaksonen DE, Lakka TA, Niskanen LK, Kumpusalo E, Tuomilehto J, Salonen JT: The metabolic syndrome and total and cardiovascular disease mortality in middle-aged men. JAMA 2002, 288:2709-2716.

4. Haffner SM, Lehto S, Rönnemaa T, Pyörälä K, Laakso M: Mortality from coronary heart disease in subjects with type 2 diabetes and in nondiabetic subjects with and without prior myocardial infarction. $N$ Engl J Med 1998, 339:229-234.

5. Sattar N, Gaw Allan, Scherbakova O, Ford I, O’Reilly D, Haffner S, Isles C, Macfarlane P, Packard C, Cobbe S, Shepherd J: Metabolic syndrome with and without C-reactive protein as a predictor of coronary heart disease and diabetes in the West of Scotland coronary prevention study. Circulation 2003, 108:414-419.

6. Stocker R, Keaney JF Jr: Role of oxidative modifications in atherosclerosis. Physiol Rev 2004, 84:1381-1478.

7. Sigurdardottir $\vee$, Fagerberg B, Hulthe J: Circulating oxidized low-density lipoprotein (LDL) is associated with risk factors of the metabolic syndrome and LDL size in clinically healthy 58-year-old men. J Intern Med 2002, 252:440-447.

8. Holvoet P, Vanhaecke J, Janssens S, Van de Werf F, Collen D: Oxidized LDL and malondialdehyde-modified LDL in patients with acute coronary syndromes and stable coronary artery disease. Circulation 1998, 98:1487-1494.

9. Hulthe J, Fagerberg B: Circulating oxidized LDL is associated with subclinical atherosclerosis development and inflammatory cytokines (Air Study). Arterioscler Thromb Vasc Biol 2002, 22:1162-1167.

10. Holvoet $P$, Mertens A, Verhamme P, Bogaerts K, Beyens G, Verhaeghe R, Collen D, Muls E, Van de Werf F: Circulating oxidized LDL is a useful marker for identifying patients with coronary artery disease. Arterioscler Thromb Vasc Biol 2001, 21:844-848.

11. Cohn JN, Finkelstein S, McVeigh G, Morgan D, LeMay L, Robinson J, Mock J: Noninvasive pulse wave analysis for the early detection of vascular disease. Hypertension 1995, 26:503-508.

12. Laurent S, Cockcroft J, Van Bortel L, Boutouyrie P, Giannattasio C, Hayoz D, Pannier B, Vlachopoulos C, Wilkinson I, Struijker-Boudier H, European Network for Non-invasive Investigation of Large Arteries: Expert consensus document on arterial stiffness: methodological issues and clinical applications. Eur Heart J 2006, 27:2588-2605.

13. De Lorgeril M, Salen P, Martin JL, Monjaud I, Delaye J, Mamelle N: Mediterranean diet, traditional risk factors, and the rate of cardiovascular complications after myocardial infarction: final report of the Lyon Diet Heart Study. Circulation 1999, 99:779-785.

14. Trichopoulou A, Costacou T, Bamia C, Trichopoulos D: Adherence to a Mediterranean diet and survival in a Greek population. N Engl J Med 2003, 348:2599-2608.

15. Kratz M, Cullen P, Kannenberg F, Kassner A, Fobker M, Abuja PM, Assmann G, Wahrburg U: Effects of dietary fatty acids on the composition and oxidizability of low-density lipoprotein. Eur J Clin Nutr 2002, 56:72-81.

16. Cicero A, Nascetti S, López-Sabater M, Elosua R, Salonen J, Nyyssönen K, Poulsen H, Zunft H-J, Kiesewetter $\mathrm{H}$, de la Torre K, Covas M, Kaikkonen J, Mursu J, Koenbick C, Bäumler H, Gaddi A, EUROLIVE study group: Changes in LDL fatty acid composition as a response to olive oil treatment are inversely related to lipid oxidative damage: the EUROLIVE study. $J$ Am Coll Nutr 2008, 2:314-320.

17. Moreno J, López-Miranda J, Péreez-Martínez P, Marín C, Moreno R, Gómez P, Paniagua J, Pérez-Jiménez F: A monounsaturated fatty acid-rich diet reduces macrophage uptake of plasma oxidised low-density lipoprotein in healthy young men. Br J Nutr 2008, 100:569-575.

18. Anderson BM, Ma DWL: Are all n-3 polyunsaturated fatty acids created equal? Lipids Health Dis 2009, 8:33.

19. Pohjantähti-Maaroos H, Palomäki A, Kankkunen P, Laitinen R, Husgafvel S, Oksanen K: Circulating oxidized low-density lipoproteins and arterial elasticity: comparison between men with metabolic syndrome and physically active counterparts. Cardiovasc Diabetol 2010, 9:41. 
20. Vuorela S, Meyer A, Heinonen M: Quantitative analysis of the main phenolics in rapeseed meal and oils processed differently using enzymatic hydrolysis and HPLC. Eur Food Res Technol 2003, 217:517-523.

21. Mattila P, Pihlava JM, Hellström J: Contents of phenolic acids, alkyl- and alkenylresorcinols, and avenanthramides in commercial grain products. $J$ Agric Food Chem 2005, 53:8290-8295.

22. Nathan DM, Kuenen J, Borg R, Zheng H, Schoenfeld D, Heine RJ, A1CDerived Average Glucose Study Group: Translating the A1C assay into estimated average glucose values. Diabetes Care 2008, 31:1473-1478.

23. Valsta LM, Jauhiainen M, Aro A, Katan MB, Mutanen M: Effects of a monounsaturated rapeseed oil and a polyunsaturated sunflower oil diet on lipoprotein levels in humans. Arterioscler Thromb 1992, 12:50-57.

24. Seppänen-Laakso T, Vanhanen $H$, Laakso I, Kohtamaki H, Viikari J: Replacement of margarine on bread by rapeseed and olive oils: effects on plasma fatty acid composition and serum cholesterol. Ann Nutr Metab 1993, 37:161-174.

25. Gulesserian T, Widhalm K: Effect of a rapeseed oil substituting diet on serum lipids and lipoproteins in children and adolescents with familial hypercholesterolemia. J Am Coll Nutr 2002, 21:103-108.

26. Vermunt $S$, Beaufrère B, Riemersma R, Sébédio J, Chardigny J, Mensink R, TransLinE Investigators a: Dietary trans alpha-linolenic acid from deodorised rapeseed oil and plasma lipids and lipoproteins in healthy men: the TransLinE Study. Br J Nutr 2001, 85:249-250.

27. Fitó M, Guxens M, Corella D, Sáez G, Estruch R, de la Torre R, Francés F, Cabezas C, López-Sabater M, Marrugat J, Garcia-Arellano A, Arós F, RuizGutierrez V, Ros E, Salas-Salvadó J, Fiol M, Solá R, Covas M, PREDIMED Study Investigators: Effect of traditional Mediterranean diet on lipoprotein oxidation. Arch Intern Med 2007, 167:1195-1203.

28. Egert S, Kratz M, Kannenberg F, Fobker M, Wahrburg U: Effects of high-fat and low-fat diets rich in monounsaturated fatty acids on serum lipids, LDL size and indices of lipid peroxidation in healthy non-obese men and women when consumed under controlled conditions. Eur J Nutr 2010.

29. Perez-Martinez P, Garcia-Quintana J, Yubero-Serrano E, Tasset-Cuevas I, Tunez I, Garcia-Rios A, Delgado-Lista J, Marin C, Perez-Jimenez F, Roche H, Lopez-Miranda : Postprandial oxidative stress is modified by dietary fat: evidence from a human intervention study. Clin Sci 2010, 119:251-261.

30. Perona S, Montero E, Sánchez-Dominíguez J, Cañizares J, Garcia M, RuizGutiérrez V: Evaluation of the effect of dietary virgin olive oil on blood pressure and lipid composition of serum and low-density lipoprotein in elderly type 2 diabetic subjects. J Agric Food Chem 2009, 57:11427-11433.

31. Tanigawa H, Miura S, Zhang B, Uehara Y, Matsuo Y, Fujino M, Sawamura T Saku K: Low-density lipoprotein oxidized to various degrees activates ERK1/2 through Lox-1. Atherosclerosis 2006, 188:245-250.

32. Meisinger C, Baumert J, Khuseyinova N, Loewel H, Koenig W: Plasma oxidized low-density lipoprotein, a strong predictor for acute coronary heart disease events in apparently healthy, middle-aged men from the general population. Circulation 2005, 112:651-657.

33. Kotani K, Yamada S, Uurtya S, Yamada T, Taniguchi N, Sakurabayashi I: The association between blood glucose and oxidized lipoprotein(a) in healthy young women. Lipids Health Dis 2010, 9:103.

34. Volek JS, Phinney SD, Forsythe CE, Quann EE, Wood RJ, Puglisi MJ, Kraemer WJ, Bibus DM, Fernandez ML, Feinman RD: Carbohydrate restriction has a more favourable impact on the metabolic syndrome than low fat diet. Lipids 2009, 44:297-309.

35. Leite JO, DeOgburn R, Ratliff J, Su R, Smyth JA, Volek JS, McGrane MM, Dardik A, Fernandez ML: Low-carbohydrate diets reduce lipid accumulation and arterial inflammation in guinea pigs fed a highcholsterol diet. Atherosclerosis 2010, 209:442-448.

36. Marchioli R, Barzi F, Bomba E, Chieffo C, Di Gregorio D, Di Mascio R, Franzosi MG, Geraci E, Levantesi G, Maggioni AP, Mantini L, Marfisi RM, Mastrogiuseppe G, Mininni N, Nicolosi GL, Santini M, Schweiger C, Tavazzi L, Tognoni G, Tucci C, Valagussa F, GISSI-Prevenzione Investigators: Early protection against sudden death by $n-3$ polyunsaturated fatty acids after myocardial infarction: time-course analysis of the results of the Gruppo Italiano per lo Studio della Sopravvivenza nell'Infarto Miocardico (GISSI)-Prevenzione. Circulation 2002, 105:1897-1903.

37. De Graaf J, Hak-Lemmers HL, Hectors MP, Demacker PN, Hendriks JC, Stalenhoef AF: Enhanced susceptibility to in vitro oxidation of the dense low density lipoprotein subfraction in healthy subjects. Arterioscler Thromb 1991, 11:298-306
38. Schwab US, Sarkkinen ES, Lichtenstein AH, Li Z, Ordovas JM, Schaefer EJ, Uusitupa Ml: The effect of quality and amount of dietary fat on the susceptibility of low density lipoprotein to oxidation in subjects with impaired glucose tolerance. Eur J Clin Nutr 1998, 52:452-458.

39. Cicerale $S$, Lucas $L$, Keast R: Biological activities of phenolic compounds present in virgin olive oil. Int J Mol Sci 2010, 11:458-479.

40. McVeigh GE, Brennan GM, Cohn JN, Finkelstein SM, Hayes RJ, Johnston GD: Fish oil improves arterial compliance in non-insulin-dependent diabetes mellitus. Arterioscler Thromb 1994, 14:1425-1429.

41. Ros E, Nunez I, Perez-Heras A, Serra M, Gilabert R, Casals E, Deulofeu R: A walnut diet improves endothelial function in hypercholesterolemic subjects. Circulation 2004, 109:1609-1614.

42. Cortés B, Núñez I, Cofán M, Gilabert R, Pérez-Heras A, Casals E, Deulofeu R, Ros E: Acute effects of high-fat meals enriched with walnuts or olive oil on postprandial endothelial function. J Am Coll Cardiol 2006, 48:1666-1671.

43. Leaf A: Cardiovascular effects of fish oils: beyond the platelet. Circulation 1990, 82:624-628.

44. Araujo MC, Yokoo EM, Pereira RA: Validation and calibration of a semiquantitative food frequency questionnaire designed for adolescents. J Am Diet Assoc 2010, 110:1170-1177.

45. Kratz M, Callahan HS, Yang PY, Matthys CC, Weigle DS: Dietary n-3polyunsaturated fatty acids and energy balance in overweight or moderately obese men and women: a randomized controlled trial. Nutr Metab 2009, 6:24.

46. Brehm BJ, Lattin BL, Summer SS, Boback JA, Gilchrist GM, Jandacek RJ, D'Alessio DA: One-year comparison of a high-monounsaturated fat diet with a high-carbohydrate diet in type 2 diabetes. Diabetes Care 2009, 32:215-220.

47. Leong XF, Mustafa MR, Das S, Jaarin K: Association of elevated blood pressure and impaired vasorelaxation in experimental Sprague-Dawley rats fed with heated vegetable oil. Lipids Health Dis 2010, 9:66.

48. Srivastava S, Singh M, George J, Bhui K, Murari Saxena A, Shukla Y: Genotoxic and carcinogenic risks associated with the dietary consumption of repeatedly heated coconut oil. Br J Nutr 2010.

49. Bloomer RJ, Kabir MM, Marshall KE, Canale RE, Farney TM: Postprandial oxidative stress in response to dextrose and lipid meals of differing size. Lipids Health Dis 2010, 9:79.

doi:10.1186/1476-511X-9-137

Cite this article as: Palomäki et al:: Effects of dietary cold-pressed turnip rapeseed oil and butter on serum lipids, oxidized LDL and arterial elasticity in men with metabolic syndrome. Lipids in Health and Disease 2010 9:137.

\section{Submit your next manuscript to BioMed Central and take full advantage of:}

- Convenient online submission

- Thorough peer review

- No space constraints or color figure charges

- Immediate publication on acceptance

- Inclusion in PubMed, CAS, Scopus and Google Scholar

- Research which is freely available for redistribution

Submit your manuscript at www.biomedcentral.com/submit
C) Biomed Central 